\title{
INTEGRASI DAN PENGEMBANGAN SISTEM MACHINE LEARNING PADA KEGIATAN MAINTENANCE UNIT BGMF PT. FI
}

\author{
INTEGRATION AND DEVELOPMENT MACHINE LEARNING SYSTEM ON MAINTENANCE ACTIVITY \\ AT BGMF UNIT PT. FI
}

\author{
Rio Restu Viryawan*)1, Arif Imam Suroso", Rokhani Hasbullah**) \\ *)Sekolah Bisnis, IPB University \\ Jl. Raya Pajajaran Bogor 16151, Indonesia \\ ${ }^{* *}$ Departemen Teknik Mesin dan Biosistem, Fakultas Teknologi Pertanian, IPB University \\ Jl. Lingkar Akademik, Kampus IPB Dramaga, Bogor 16002, Indonesia
}

\begin{abstract}
The Big Gossan Mill Facility (BGMF) unit has a vital function to deliver tailing supporting Big Gossan underground mining. Plant maintenance strategies have been implemented to support its availability. This study aims to study integration of machine learning model into the plant maintenance and to formulate development of Machine Learning System in BGMF unit. The maintenance planning standards is used to integrate Machine Learning model through interview. The Industrial Internet Reference Architecture (IIRA) is applied to develop machine learning system. It uses interview method to formulate business viewpoint and usage viewpoint and observation to elaborate functional viewpoint and implementation viewpoint. The study results integration of machine learning model is done by state it as PD-200 Propelling Liquid alarm. It then should be followed up by the planning crew. The machine learning system development starts with formulation of Key Objectives and Fundamental Capabilities on the business viewpoint. The usage viewpoint defines two scenarios on machine learning system. The functional viewpoint elaborates system functionality. The implementation viewpoint designed network topology. It then emphasizes on key system characteristics. This research concludes that model integration into plant maintenance can minimize PD-200's downtime and it's system design can be done by IIRA.
\end{abstract}

Keywords: IIRA, machine learning, maintenance improvement, predictive maintenance, predictive model

\begin{abstract}
Abstrak: Unit Big Gossan Mill Facility (BGMF) mempunyai fungsi vital dalam pengiriman tailing untuk mendukung kegiatan tambang bawah tanah Big Gossan. Berbagai strategi perawatan pabrik telah diterapkan untuk mendukung availability yang tinggi. Penelitian ini bertujuan untuk mengkaji integrasi model machine learning pada kegiatan perawatan pabrik dan merumuskan pengembangan sistem machine learning di Unit BGMF PTFI. CrossIndustry Standard Process for Data Mining (CRISP-DM) digunakan untuk megembangkan model dan penerapannya. Penerapan model juga mengacu pada Maintenance Planning Standards dengan metode wawancara dan The Industrial Internet Reference Architecture (IIRA) untuk mengembangkan sistem. Metode wawancara digunakan untuk merumuskan sudut pandang bisnis dan kegunaan dan metode observasi digunakan untuk merumuskan sudut pandang fungsional dan implementasi. Hasil penelitian menunjukkan integrasi dilakukan dengan menjadikan luaran model menjadi alarm Propelling Liquid pompa PD-200 yang perlu ditindaklanjuti oleh kru perencana. Pengembangan sistem machine learning dimulai dari perumusan Key Objectives dan Fundamental Capabilities pada sudut pandang bisnis. Dua skenario penggunaan sistem dijelaskan pada sudut pandang kegunaan. Fungsionalitas sistem dijelaskan pada sudut pandang fungsional. Topologi jaringan dirumuskan pada sudut pandang implementasi. IIRA kemudian memberikan penekanan pada karakterisitik kunci sistem. Kesimpulan dari penelitian ini menunjukkan bahwa integrasi model pada perawatan pabrik dapat meminimalkan downtime pompa PD-200 dan perumusan desain sistemnya dapat menggungakan IIRA.
\end{abstract}

Kata kunci: IIRA, machine learning, maintenance improvement, model prediktif, perawatan prediktif

\footnotetext{
${ }^{1}$ Corresponding author:

Email: viryawanrio@gmail.com
} 


\section{PENDAHULUAN}

Unit Big Gossan Mill Facility (BGMF) PT. Freeport Indonesia (PTFI) mempunyai fungsi vital dalam mengirimkan tailing ke unit pengolahan untuk mendukung kegiatan pertambangan bawah tanah Big Gossan. Tailing dimanfaatkan untuk pembuatan pasta, sebagai backfill yang digunakan pada penambangan "open stope with paste backfill". Tambang ini merupakan tambang dengan grade emas dan tembaga yang tinggi, sehingga penting untuk dijaga keberlangsungan operasinya.

Berbagai strategi perawatan telah diterapkan pada unit ini untuk mendukung availability yang tinggi. Strategi perawatan ini antara lain: corrective maintenance (Tindakan perbaikan bila terjadi kerusakan); Preventive Maintenance (Tindakan pencegahan yang dilakukan dengan berdasarkan rentang waktu atau running hours tertentu); predictive maintenance (condition monitoring dengan menggunakan metode Tribology, Vibration Analysis, dan Infra Red).

Dengan perkembangan industri 4.0, penerapan predictive maintenance dapat ditingkatkan efisiensi dan efektivitasnya (Çınar et al. 2020; Chukwuekwe, 2016; OSIsoft, 2018). Pengertian machine learning menurut Mitchell dalam Ertel (2017) adalah studi tentang algoritma komputer yang berkembang secara otomatis melalui pengalaman. Machine learning telah memungkinkan untuk mengembangkan suatu model yang dilatih melalui rekaman data input dan karakteristik luaran untuk memprediksi suatu kegagalan (Mathew et al. 2017). Penelitian sebelumnya yang terkait predictive maintenance:

1 Cárdenas-Gallo et al. (2017): regresi logistik pada prediksi track geometry degradation.

2 Quiroz et al. (2018): fault detection kerusakan rotor bar pada Line Start-Permanent Magnet Synchronous Motor (LS-PMSM).

3 Kaparthi dan Bumblauskas (2020): prediksi kerusakan drive pada data center.

4 Keartland dan Zyl (2020): Analisis oli gearbox untuk klasifikasi kondisi mesin.

Model machine learning telah berhasil dikembangkan untuk memprediksi problem propelling liquid pressure pompa PD-200 Unit BGMF. Penelitian ini berfokus pada penerapan setelah model dengan kinerja terbaik berhasil didapatkan. Pada metode CRISP-DM, penelitian berfokus pada langkah deployment.
Penerapan model machine learning untuk predictive maintenance pada perawatan pabrik yang sudah ada perlu mengacu kepada maintenance planning Standards dan alur perawatan pabrik. Agar model dapat menjalankan fungsinya, model perlu dikembangkan menjadi sebuah sistem. Dengan mengacu kepada IIRA, interaksi dengan sistem lain digambarkan pada sudut pandang fungsional. Dengan demikian model dapat berkerja dengan efektif dan memberikan nilai tambah pada kegiatan perawatan pabrik di unit BGMF.

Penelitian ini bertujuan mengkaji bagaimana integrasi model machine learning pada kegiatan perawatan pabrik di unit BGMF. Tujuan selanjutnya adalah merumuskan pengembangan sistem machine learning pada unit BGMF.

\section{METODE PENELITIAN}

Penelitian dilakukan selama empat bulan (FebruariMei 2021) di unit BGMF PTFI. Data yang digunakan pada kajian proses integrasi model Machine learning pada kegiatan perawatan pabrik adalah data primer yang didapatkan dari wawancara semi-structured pada staf perencana. Data yang digunakan pada perumusan pengembangan sistem sudut pada pandang bisnis dan kegunaan machine learning di Pabrik Konsentrat PTFI adalah data primer yang didapatkan dari wawancara semi-structured pada senior manager Cconcentrating maintenance, sedangkan untuk merumuskan sudut pandang fungsional dan implementasi digunakan metode observasi.

Data yang digunakan pada kajian integrasi model machine learning pada kegiatan perawatan pabrik didapatkan dari wawancara semi-structured pada staf perencana. Narasumber ini menjadi relevan karena Departemen Perencanaan Perawatan Pabrik bertanggung jawab terhadap semua perencanaan kegiatan perawatan pabrik. Pada perumusan pengembangan sistem machine learning di Pabrik Konsentrat PTFI. Data didapatkan dari wawancara semi-structured pada senior manager concentrating maintenance. Narasumber ini menjadi relevan karena pengetahuannya mengenai gambaran keseluruhan kegiatan perawatan pabrik, berbagai kepentingan bisnis di dalamnya dan bagaimana penanganannya.

Penerapan model mengikuti langkah deployment pada Cross-Industry Standard Process for Data Mining 
(CRISP-DM). Pada konteks perawatan pabrik di PTFI, langkah ini terdiri dari kajian integrasi model machine learning pada kegiatan perawatan pabrik dan pengembangan model menjadi suatu sistem.

Metode kualitatif digunakan pada kajian integrasi model machine learning pada kegiatan perawatan pabrik. Alat yang digunakan adalah PTFI maintenance planning Standards dan alur perawatan pabrik. Dokumen PTFI Maintenance Planning Standards mencakup ketentuan mengenai seluruh kegiatan perencanaan perawatan pabrik di PTFI. Alur perawatan pabrik menunjukkan alur kegiatan perawatan elektrikal, instrumen, dan mekanikal di Divisi Concentrating. Luaran dari langkah ini adalah integrasi machine learning pada perawatan pabrik yang ada.

Metode kualitatif digunakan pada pengembangan model menjadi suatu sistem. Alat yang digunakan adalah The Industrial Internet Reference Architecture (IIRA). Kerangka acuan IIRA digagas dari kalangan industri (Yli-Ojanperä, et al. 2018), sehingga diharapkan cocok untuk diterapkan di PTFI. Machine learning menjadi topik yang dijelaskan pada kerangka ini. Inisiatif untuk menerapkan kerangka ini mengacu kepada dokumentasi testbed (Weber et al. 2017). Luaran dari langkah ini adalah architecture description penerapan machine learning pada pabrik konsentrat.

Penelitian diawali dengan mengkaji bagaimana integrasi model machine learning pada kegiatan perawatan pabrik, dilanjutkan dengan perumusan pengembangan sistem machine learning pada Pabrik Konsentrat PTFI. Penelitian kemudian dilanjutkan dengan perumusan implikasi manajerial penerapan Machine learning. Kerangka pemikiran penelitian ditunjukkan pada Gambar 1.

\section{HASIL}

\section{Integrasi Model Machine Learning Pada Kegiatan Perawatan Pabrik}

Luaran dari model machine learning ini akan menjadi alarm Propelling Liquid PD-200 (Kanawaday dan Sane 2017; Taehoon et al. 2017; Kroll et al. 2014). Alarm ini menjadi bagian dari temuan Condition Monitoring pada alur kegiatan perawatan mekanis dan elektrik/ instrumentasi pada Divisi Concentrating, dan perlu dijadwalkan untuk ditindaklanjuti oleh kru perencana
(Gambar 2). Pengecekan dapat dilakukan pada saat Unit BGMF stand by. Suatu dedicated dashboard dapat disediakan untuk menampilkan berbagai informasi dari model (Calabrese et al. 2020).

Tindakan preventif yang dapat dilakukan antara lain dengan melakukan kontrol terhadap variabel yang mempengaruhi tekanan propelling liquid. Bila tindakan perawatan ini efektif sepenuhnya dan dengan asumsi catatan kejadian breakdown BGMF tahun 2020, maka diperkirakan model ini dapat membantu menurunkan downtime sebesar $33,8 \%$, dan perkiraan total biaya perawatan tak terduga yang dapat dihemat adalah sebesar $32,27 \%$.

\section{Pengembangan Sistem Machine Learning Pada Pabrik Konsentrat Unit BGMF}

Kerangka IIRA terdiri dari sudut pandang Bisnis, sudut pandang Kegunaan, sudut pandang Fungsional, dan sudut pandang Implementasi (IIC, 2019). Kerangka ini bertujuan sebagai model yang komprehensif suatu Industrial Internet untuk berbagai sektor industri, dengan berdasarkan ISO/IEC/IEEE 42010:2011 (Bader et al. 2019). Pada sudut pandang Bisnis dirumuskan Key Objectives dan Fundamental Capabilities dari sistem Machine learning yang akan dikembangkan. Key Objectives diturunkan dari Visi dan Misi serta nilainilai perusahaan. Pada konteks kegiatan perawatan pabrik, tujuan penerapan Machine learning sebagai pengembangan kegiatan perawatan pabrik tidak boleh melenceng dari tujuan utama kegiatan perawatan pabrik, yaitu availability yang tinggi pada peralatan pabrik. Hal ini dicapai dengan penekanan pada strategi pencegahan (preventif) daripada langkah kuratif.

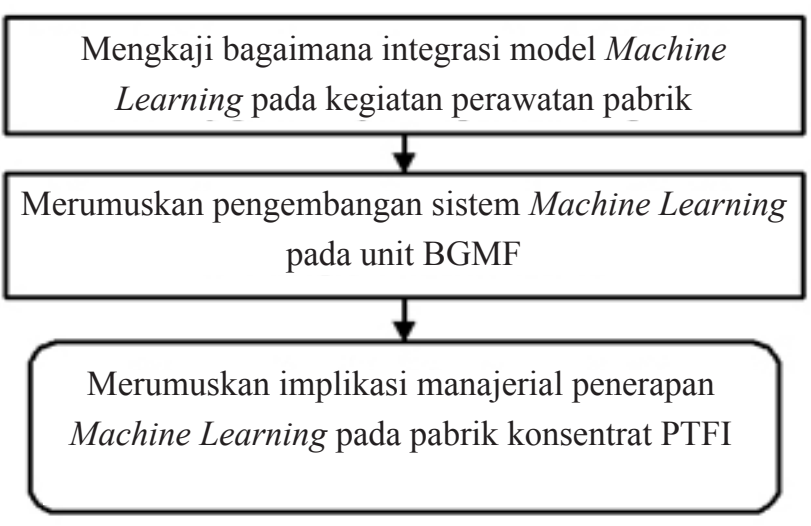

Gambar 1. Kerangka pemikiran penelitian 


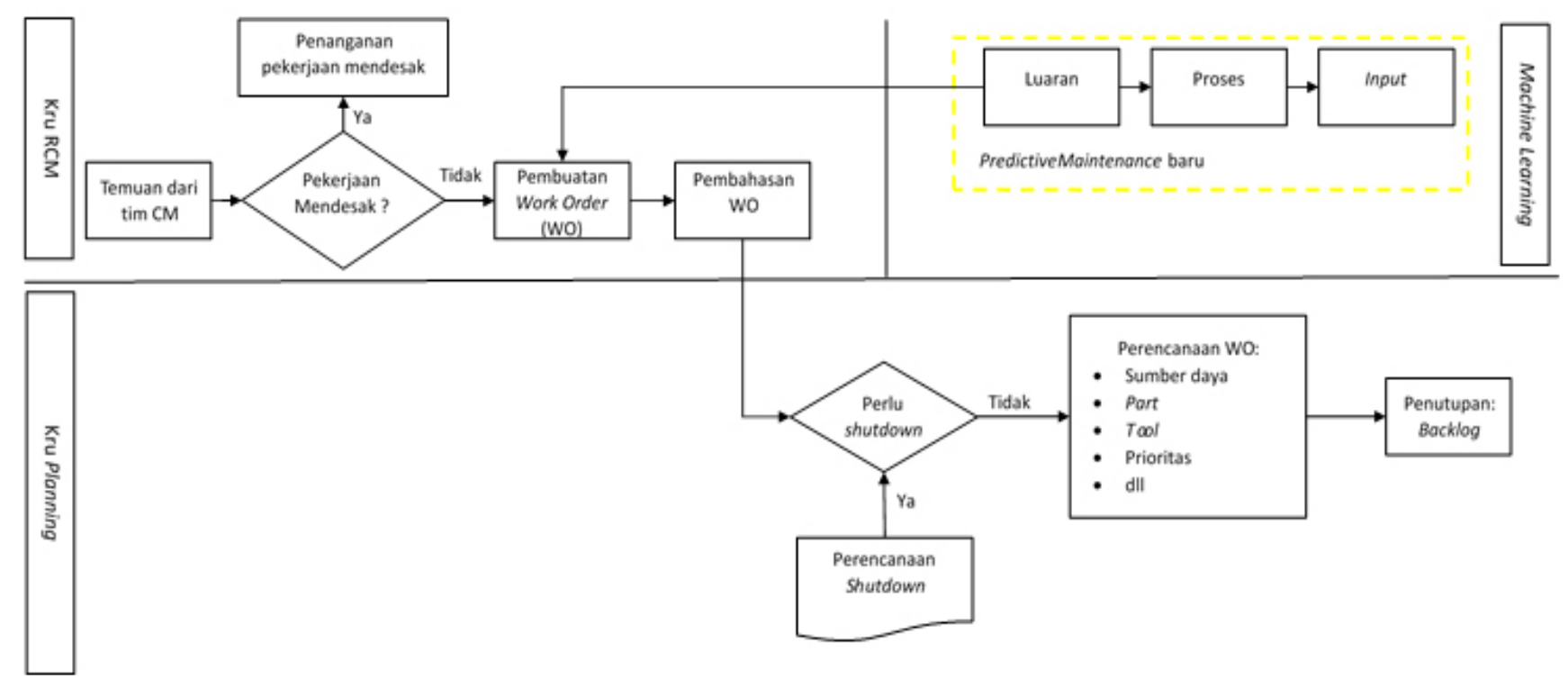

Gambar 2. Integrasi Machine Learning pada alur kegiatan perawatan pabrik di PTFI

Key Objectives adalah hasil pada tingkatan bisnis yang dapat dikuantifikasi pada tingkatan high-level yang diharapkan yang dihasilkan dari sistem yang dibangun dalam konteks menciptakan nilai (IIC, 2019). Rumusan Key Objectives yang dihasilkan dari proses wawancara adalah sebagai berikut: mengoptimalkan aktivitas Preventive Maintenance dalam meminimalisir Breakdown; Improvement dalam Health Condition Monitoring; meminimalisir terulangnya problem yang sama; meningkatkan availability dari peralatan.

Fundamental Capabilities adalah spesifikasi pada tingkat high-level terhadap kemampuan esensial suatu sistem untuk menyelesaikan penugasan bisnis yang spesifik (IIC, 2019). Rumusan Fundamental Capabilities adalah sebagai berikut: mengembangkan sistem Machine learning dengan kemampuan Predictive Maintenance; mengembangkan sistem Machine learning untuk mengungkap pengetahuan yang berguna untuk proses perawatan pabrik; mengembangkan sistem Machine learning dengan konektifitas sensorsensor di pabrik; mempunyai interkonektivitas dengan sistem yang terpakai seperti DCS, Plant Information (PI), dan SAP; infrastruktur sistem Machine learning memenuhi persyaratan dari tim Data Center MIS PTFI; mengembangkan sistem Machine learning yang mempunyai konektifitas dengan sistem perakaman.
Pada sudut pandang Kegunaan, interaksi antara aktor, peran dan aktivitas dijabarkan. Dua skenario penggunaan sistem Machine learning adalah sebagai berikut: Training (tahapan pengembangan model Machine learning)(Gambar 3) dan Predicting (model Machine learning yang digunakan untuk memprediksi luaran) (Gambar 4).

Sudut pandang Fungsional memeriksa sistem yang akan dibangun dari 5 perspektif fungsional (Gambar 5). Pada domain kontrol, fungsi utama pengontrolan BGMF dijalankan oleh Programmable Logic Control (PLC) dan Distributed Control System (DCS). Perangkat kontrol ini terhubung ke sensor-sensor dan aktuator dalam menjalankan fungsinya. Antarmuka dengan operator dijalankan oleh fungsi Human-Machine Interface (HMI). Bacaan dari berbagai sensor diakuisisi datanya dengan protokol standar, yaitu OPC Standard (Guo et al. 2012). Integrasi data ini memungkinkan untuk pengolahan dan analisis data lebih lanjut sehingga memberikan informasi dan pengetahuan yang lebih bernilai (Carvalho et al. 2019).

Pada domain operasi, operasi BGMF dilakukan melalui HMI. HMI ini yang memungkinan operator mengoperasikan alat-alat di unit BGMF. Alarm dan peringatan akan disediakan pada program HMI dan dipantau oleh Operator. Alarm ini antara lain indikasi level tangki rendah, tekanan propelling liquid rendah, temperatur tinggi, dan lain-lain. 


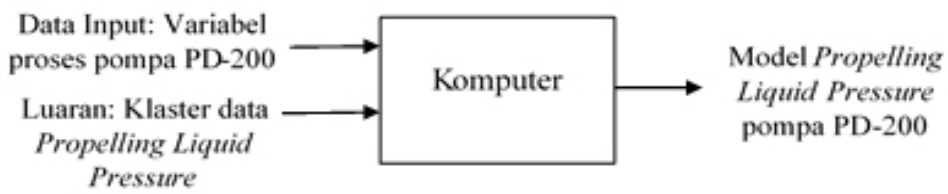

Gambar 3. Skenario Training

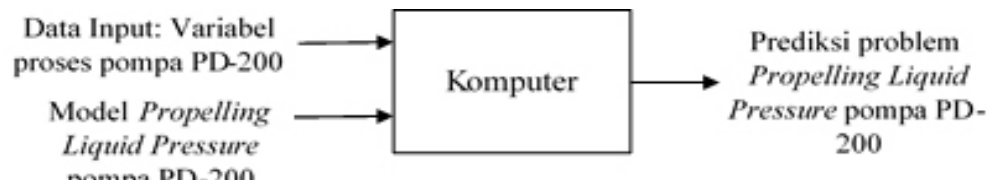

Gambar 4. Skenario Predicting
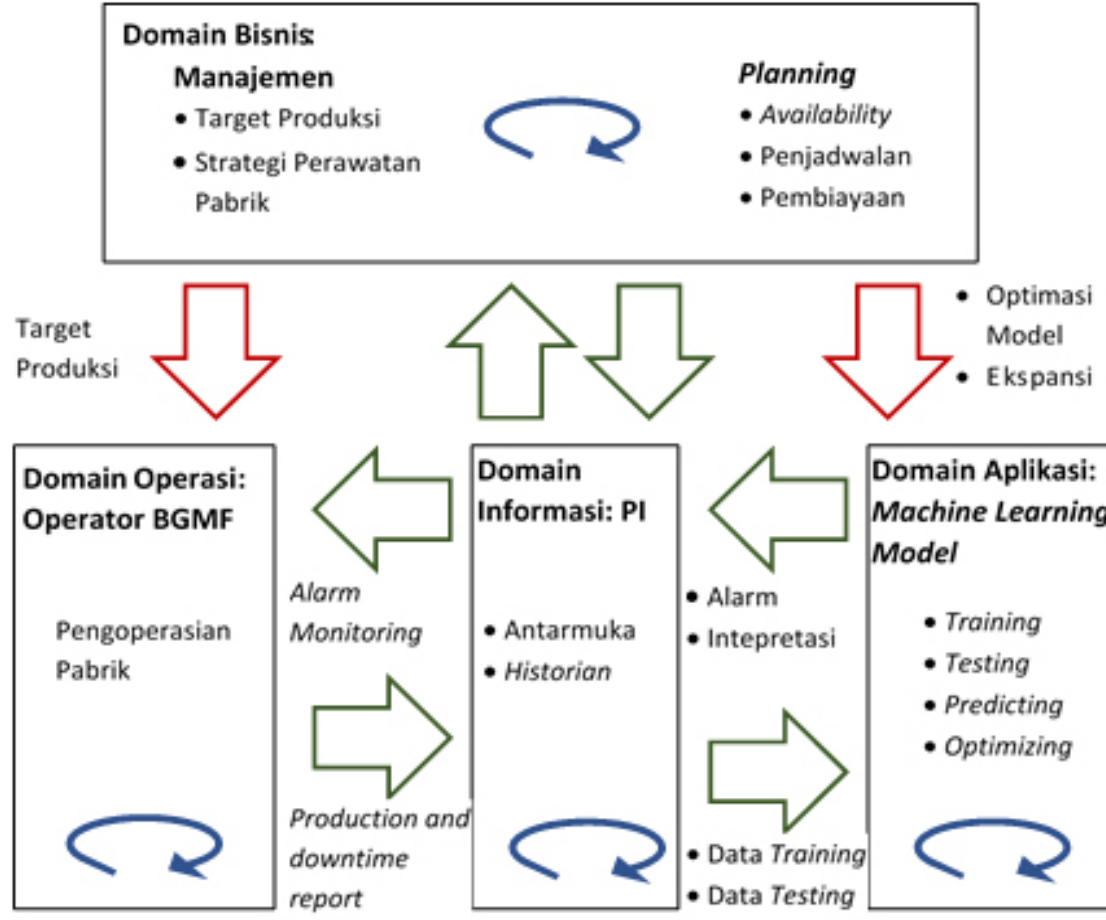

Domain Aplikasi: Machine Learning Model

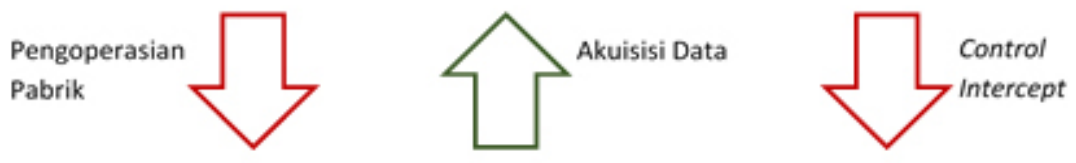

$$
\begin{aligned}
\text { Domain Kontrol: PLC \& DCS } \\
\\
\bullet \text { Plant Control } \\
\bullet \text { HMI }
\end{aligned}
$$

Sensor

Aktuator

Gambar 5. Domain fungsional sistem Machine Learning 
Pada domain informasi, aplikasi PI memegang peranan penting. Antarmuka dengan berbagai perangkat dilakukan oleh aplikasi ini. Aplikasi ini juga melakukan perekaman terhadap data yang diakuisisi untuk berbagai kepentingan. Aplikasi ini menyediakan data yang digunakan Machine learning untuk kegunaan Training, Testing dan Predicting. Luaran dari model diumpankan pada domain ini, untuk kemudian diteruskan ke grup perencana pada domain bisnis.

Pada domain aplikasi, aplikasi Machine learning diterapkan untuk mendeteksi anomali pada aset. Luaran dari Machine learning dapat intervensi langsung ke domain kontrol sebagai tindakan preventif. Pengembangan model Machine learning adalah berdasarkan kebutuhan bisnis, dan dapat dikembangkan ke area lain.

Pada domain bisnis, informasi dini anomali pada PD200 akan dijadwalkan pada SAP untuk ditindaklanjuti. Kru perencana akan melihat jadwal operasional BGMF untuk melihat kapan BGMF stand by. Kru juga akan mempersiapkan part dan mengalokasikan biaya yang diperlukan. Manajemen menentukukan target operasi pada unit BGMF pada rentang waktu tertentu. Kegiatan perawatan pabrik harus mampu mendukung pencapaian target produksi ini. Berbagai strategi perawatan pabrik akan dievaluasi untuk melihat bagaiamana efektivitas dan efisiensinya, dan bagaimana meningkatkannya.
Topologi jaringan sistem Machine learning dirancang pada sudut pandang implementasi. Instrumen-instrumen pompa PD-200 menggunakan sinyal kontrol dan instrumentasi untuk dapat dibaca oleh Programmable Logic Control (PLC) dan Distributed Control System (DCS) di BGMF. Kedua sistem ini menjalankan fungsi kontrol utama pada BGMF. Koneksi ini berada di Device Level Network dan hal ini merupakan representasi dari Operational Technology (OT). Antarmuka operator dengan sistem kontrol BGMF difasilitasi dengan Human Machine Interface (HMI) pada DCS. Pada HMI ini ditampilkan alarm-alarm yang muncul pada alat di BGMF.

Data dari PLC dan DCS kemudian diakuisisi oleh aplikasi historian PI menggunakan protokol OPC. Data yang sudah diakuisisi diumpankan ke sistem Machine learning dan berbagai sistem lainnya. Hal ini merupakan representasi dari Information Technology (IT).

Dengan interkoneksi ini memungkinkan data-data di pabrik terhubung ke berbagai sistem pada skala enterprise. Hal ini merupakan perwujudan dari Industrial Internet of Thing (IIoT). Antarmuka antara OT dan IT ini perlu memperhatikan karakterisitik data dan informasi yang berbeda pada kedua teknologi ini. Rancangan topologi ini ditunjukkan pada Gambar 6.

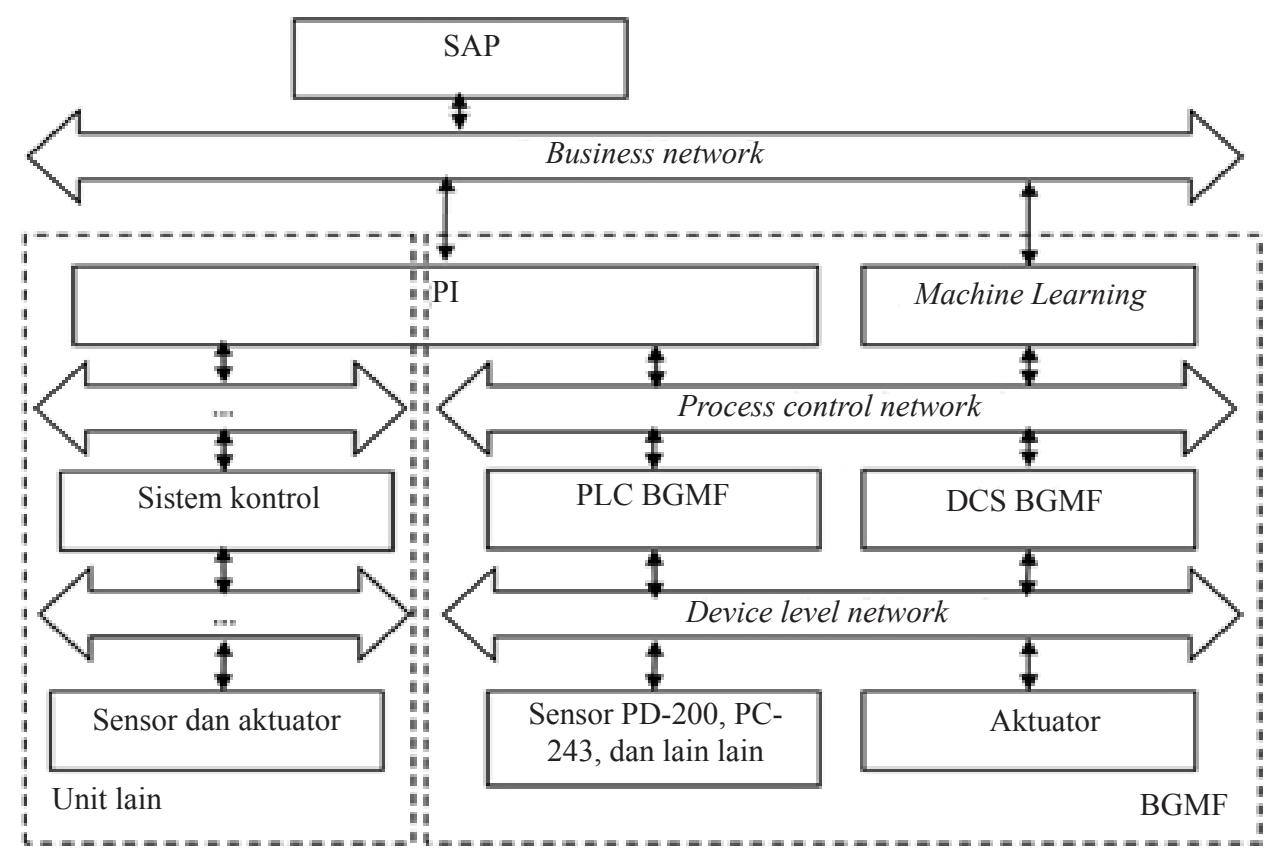

Gambar 6. Topologi jaringan sistem Machine Learning 


\section{Karakteristik Kunci Sistem}

1. Keselamatan: Pengembangan sistem Machine learning untuk Predictive Maintenance adalah bagian dari upaya pemeliharaan sarana. Hal ini merupakan bagian dari Keselamatan Operasi Pertambangan (KOP) yang telah ditetapkan oleh Kementerian Energi dan Sumber Daya Mineral (KESDM, 2019). Pada pelaksanannya, perlu dilakukan studi secara keseluruhan untuk mengidentifikasi bahaya, pengendalian resiko dan penentuan kontrol terkait dengan KOP pada unit BGMF, dimana pengembangan Predictive Maintenance ini menjadi bagian di dalamnya.

2. Keamanan dan privasi: Untuk menangani berbagai ancaman keamanan yang mungkin timbul, pengembangan sistem ini harus mematuhi ketentuan keamanan standar Data Centre PTFI.

3. Reliability and resilience: Standar Data Centre PTFI telah mengatur ketentuan terkait reliability and resilience yang harus dipenuhi. Prosedur pengoperasian sistem perlu dikembangkan sehingga sistem dapat bekerja dengan baik dan menghindari human error.

4. Performance and scalability: Sistem Machine learning diharapkan dapat menjalankan fungsi monitoring yang terus-menerus. Akurasi dan presisi dari model perlu untuk terus ditingkatkan. Model Machine learning juga dapat dikembangkan pada objek-objek lain. Oleh karena itu, perlu dilakukan penilaian mengenai kemampuan infrastruktur sistem terhadap beban kerja maksimal yang dapat ditangani.

The Industrial Internet Reference Architecture (IIRA) merupakan referensi arsitektur yang dihasilkan dari inisiatif pimpinan-pimpinan industri (Weber et al. 2017). Hal ini berimplikasi pada kecocokan penerapan referensi arsitektur pada berbagai industri. Di sini dapat dilihat ketentuan-ketentuannya relevan dengan penerapan pada industri bidang pengolahan mineral.

\section{Implikasi Manajerial}

Implikasi manajerial dari penerapan model untuk Predictive Maintenance adalah sebagai berikut:

1. Mencegah unplanned downtime: Hal ini dilakukan dengan melakukan tindakan pengontrolan variabel prediktor yang mempengaruhi problem. Hal ini juga dapat mengatasi rework karena kejadian berulang problem ini.
2. Mengurangi planned downtime: Penerapan Predictive Maintenance berbasis model dapat digunakan untuk mengevaluasi kapan penggantian suatu part diperlukan.

3. Meningkatkan produktivitas: Dengan berkurangnya downtime, maka tidak hanya biaya perawatan yang dapat dikurangi, namun juga production loss juga dapat dikurangi.

4. Optimasi penggunaan sumber daya perawatan pabrik: Penggantian part pompa dapat digunakan hingga masa pakai nya berakhir, contoh: penggantian diafragma pompa PD-200 dan interval pengisian ulang Propelling Liquid yang menjadi lebih panjang.

5. Peningkatan asset health dan performance: Pemantauan atas kinerja dan kesehatan suatu alat menjadi lebih komprehensif.

6. Meningkatkan kepuasan pelanggan. Dalam hal ini misalnya, unit tambang bawah tanah Big Gossan dapat melaksanakan kegiatan produksinya dengan lancar untuk mencapai target produksi yang ditetapkan.

Pengembangan sistem Machine learning memerlukan investasi pada hardware, software, dan organoware. Perusahaan perlu menguasai kompetensi baru ini, agar dapat bersaing pada dunia industri di masa depan (Faturohman et al. 2019). Tabel 1 menunjukkan perkiraan biaya investasi yang diperlukan, informasi harga lebih detail dapat menghubungi pihak terkait.

Tabel 1 Perkiraan besaran investasi

\begin{tabular}{ll}
\hline Investasi & Biaya \\
\hline Pengadaan unit server & $2.939,51$ USD (1 unit) \\
Pengadaan software Machine & 10.000 USD \\
learning (Anaconda Product) & \\
Pengadaan license PI & 42.000 USD (10.000 \\
& tag) \\
Penyelenggaraan pelatihan Data & Rp. 2.500.000,- per \\
Sains dan Machine Learning & orang \\
\hline
\end{tabular}

Model Machine learning secara umum dapat dioptimalkan kinerjanya antara lain dengan penyetelan thresholding, penyetelan hyperparameter (Kotthoff, 2016), penggunaan algoritma lain (Gęca, 2020) dan penambahan sensor. Di samping itu, Sistem Machine learning ini dapat mengakomodir beberapa model dengan topologi dan fungsional yang sama. Suatu model Machine learning dapat dikembangkan bila variabelvariabel respons dan prediktornya dapat dikuantifikasi dan kemudian diakuisisi. 


\section{KESIMPULAN DAN SARAN}

\section{Kesimpulan}

Penerapan model machine learning yang dapat memprediksi kegagalan pada pompa PD-200 BGMF perlu dilakukan agar model berkerja dengan efektif dan memberikan nilai tambah pada kegiatan perawatan pabrik. Integrasi model pada kegiatan perawatan pabrik dilakukan dengan menjadikan luaran Machine learning sebagai alarm pompa PD-200. Model juga dapat membantu menentukan tindakan preventif yang efektif.

Pada penerapan di lapangan, model perlu dikembangkan menjadi sebuah sistem yang dapat dijalankan di lapangan. Perumusan desain penerapan sistem Machine learning dikembangkan dengan kerangka acuan Industrial Internet Reference Architecture (IIRA). Penjabaran dilakukan pada ke-empat sudut pandang dan penekanan karakteristik kunci sistem.

\section{Saran}

Model machine learning ini dapat diterapkan pada bidang lain di PTFI. Perlu dilakukan kajian tindak lanjut karakteristik kunci sistem Machine learning yang perlu dilakukan dengan melibatkan berbagai pihak terkait (K3, MIS, dan lain-lain).

\section{DAFTAR PUSTAKA}

BaderSR, Maleshkova M,Lohmann S. 2019. Structuring reference architectures for the industrial internet of things. Future Internet 11(151): 1-23. https:// doi.org/10.3390/fi11070151

Calabrese $M$ et al. 2020. SOPHIA: an eventbased iot and machine learning architecture for predictivemaintenance in industry 4.0. Information 11(202). https://doi.org/10.3390/ info11040202

Cárdenas-Gallo I et al. 2017. An ensemble classifier to predict track geometry degradation. Reliability Engineering and System Safety 161: 53-60. http://dx.doi.org/10.1016/j.ress.2016.12.012

Carvalho TP, Soares FAAMN, Vita R, Francisco RP, Basto JP, Alcalá SGS. 2019. A systematic literature review of machine learning methods applied to predictive maintenance. Computers \& Industrial Engineering 137 (2019). https://doi. org/10.1016/j.cie.2019.106024

Çınar ZM, Nuhu AA, Zeeshan Q, Korhan O, Asmael M, Safaei B. 2020. Machine learning in predictive maintenance towards sustainable smart manufacturing in industry 4.0. Sustainability 12 (8211). https://doi.org/10.3390/su12198211

Chukwuekwe DO. 2016. Condition monitoring for predictive maintenance: a tool for systems prognosis within the industrial internet applications [tesis]. Trondheim: Norwegian University of Science and Technology.

Ertel W. 2017. Introduction to Artificial Intelligence: Second Edition. Weingarten: Springer.

Faturohman, Rifin A, Djohar S. 2019. Arsitektur strategik perusahaan jasa hospitality (Studi Kasus PT Angkasa Pura Hotel). Jurnal Aplikasi Manajemen dan Bisnis 5(2): 319-331. DOI: http://dx.doi.org/10.17358/jabm.5.2.319

Gęca J. 2020. Performance comparison of machine learning algorithms for predictive maintenance. IAPGOS 2020(3): 32-35. http://doi. org/10.35784/iapgos.1834

Guo ZX, Xie XQ, Ni ZG. 2012. The application of opc da in factory data acquisition. 2012 IEEE International Conference on Computer Science and Automation Engineering (CSAE). 209-212. https://doi.org/10.1109/CSAE.2012.6272760

[IIC] Industrial Internet Consortium. 2019. The Industrial Internet of Things Volume G1: Reference Architecture. Version 1.9. (tempat tidak diketahui): Industrial Internet Consortium.

Kanawaday A, Sane A. 2017. Machine Learning for predictive maintenance of industrial machines usingIoTsensordata.2017.8th IEEEInternational Conference on Software Engineering and Service Science (ICSESS). 87-90. https://doi. org/10.1109/ICSESS.2017.8342870

Kaparthi S, Bumblauskas D. 2020. Designing predictive maintenance systems using decision tree-based machine learning techniques. International Journal of Quality \& Reliability Management 37(4):659-686. https://doi.org/10.1108/IJQRM04-2019-013

Keartland S, Zyl VTL. 2020. Automating predictive maintenance using oil analysis and machine learning. In Proceedings of the 2020 International SAUPEC/RobMech/PRASA Conference, Cape Town, South Africa, 29-31 January 2020. https://doi.org/10.1109/SAUPEC/RobMech/ PRASA48453.2020.9041003

[KESDM] Kementrian Energi dan Sumber Daya 
Mineral Republik Indonesia. 2019. Keputusan Direktur Jenderal Mineral dan Batubara Kementerian Energi dan Sumber Daya Mineral Nomor185.K/37.04/DJB/2019. (tempat tidak diketahui): Kementrian Energi dan Sumber Daya Mineral Republik Indonesia.

Kotthoff L et al. 2016. Auto-WEKA 2.0: Automatic model selection and hyperparameter optimization in WEKA. Journal of Machine Learning Research 18(25):1-5.

Kroll B, Schaffranek S, Schriegel S, Niggemann O. 2014. System modeling based on machine learning for anomaly detection and predictive maintenance in industrial plants. Proceedings of the 2014 IEEE Emerging Technology and Factory Automation (ETFA). Barcelona (ES). https://doi.org/10.1109/ETFA.2014.7005202

Mathew V, Toby T, Singh V, Rao BM, Kumar MG. 2017. Prediction of Remaining Useful Lifetime (RUL) of turbofan engine using machine learning. Proceedings of the 2017 IEEE International Conference on Circuits and Systems (ICCS 2017). 306-311.

OSIsoft. 2018. A Guidebook to Implementing ConditionBased Maintenance (CBM) Using Real-time
Data: A practical guide to getting more value from real-time data by supporting effective asset management strategies. San Leandro: OSIsoft.

Quiroz JC et al. 2018. Fault detection of broken rotor bar inLS-PMSMusing randomforests. Measurement: Journal of the International Measurement Confederation 2018(116):273-280. https://doi. org/10.1016/j.measurement.2017.11.004

Taehoon K, Je HL, Hyunchang C, Sungzoon C, Wounjoo L, Miji L. 2017. Machine learningbased anomaly detection via integration of manufacturing, inspection and after-sales service data. Industrial Management \& Data System. 117(5): 927-945. https://doi.org/10.1108/IMDS06-2016-0195

WeberC, Königsberger J, Kassner L, Mitschang B. 2017. M2DDM - A Maturity Model for Data-Driven Manufacturing. The 50th CIRP Conference on Manufacturing Systems 63:173 - 178. https:// doi.org/10.1016/j.procir.2017.03.309

Yli-Ojanperä M, Sierla S, Papakonstantinou N, Vyatkin V.2018. Adapting an agile manufacturing concept to the reference architecture model industry 4.0. Journal of Industrial Information Integration. https://doi.org/10.1016/j.jii.2018.12.002 